TOM CHRISTOPHER

\title{
Everything Rising out of Ponds
}

I was told I should not

walk around with a loaded heart,

that I could stumble and

somebody gets it in the face.

I already know about August

the unwanted free time, trying to make the perfect potato salad and writing letters to you in my head.

But really, what chance do I have, between fireflies and tree frogs screaming "fuck me" into the night, the constellation of a soup can tucked in the corner of the sky, the beautiful halo of the Mennonite baseball diamond on the horizon.

Something three molecules thick is biting my arm and you tell me mosquitoes are born from water but so are the dragonflies who eat them so why can't the ponds just keep it to themselves?

At times I wish I were a fruit fly intoxicated in the arms of an overripe banana. That shamble of atoms pausing for one day before falling apart into cogs and dust.

And I am pausing before letting my hands clatter over you like tin cans on asphalt. 
Pausing like the moment between when the coffee mug is dropped and shatters over the floor and you realize you are barefoot and the cat is running in. Inside my stomach there are fields of corn blowing in the wind, no, the fields are running marathons and then we shudder into plate tectonics the plasmatic explosions of dandelion blooms drowning in the futile oceans our bodies are dumping.

And hours after the adrenal gland falls asleep drooling, I hear the dawn hung over and crashing through the fields.

Your hand is on my chest unaware of the soft Morse code please. stop. don't leave me. stop. down here we are breaking in two. 